\title{
Neurological involvement in childhood Evans syndrome
}

Thomas Pincez, ${ }^{1 *}$ Bénédicte Neven, ${ }^{2,3}$ Hubert Ducou Le Pointe, ${ }^{4}$ Pascale Varlet, ${ }^{5}$ Helder Fernandes, ${ }^{6,7}$ Albane Gareton, ${ }^{5}$ Guy Leverger, ${ }^{1}$ Thierry Leblanc, ${ }^{8}$ Hervé Chambost, ${ }^{9}$ Gérard Michel, ${ }^{9}$ Marlène Pasquet, ${ }^{10}$ Frédéric Millot, ${ }^{11}$ Olivier Hermine, ${ }^{12}$ Alexis Mathian, ${ }^{13}$ Marie Hully, ${ }^{14}$ Hélène Zephir, ${ }^{15}$ Mohamed Hamidou, ${ }^{16}$ Jean-Marc Durand, ${ }^{17}$ Yves Perel,,${ }^{6,7,18}$ Judith Landman-Parker, ${ }^{1}$ Fréderic Rieux-Laucat, ${ }^{3}$ and Nathalie Aladjidi. ${ }^{6,7,18}$

\section{Running title: Neurological involvement in Evans syndrome}

1 Department of Onco-Hematology, APHP -Trousseau Hospital, Paris, France

2 Pediatric Hematology-Immunology Department, APHP- Necker-Enfants Malades Hospital, Paris, France 3 Immunogenetics of Pediatric Autoimmune Diseases, Institut Imagine, INSERM UMR-S1163, Paris Descartes University, Paris, France

4 Pediatric Radiology department, APHP - Trousseau Hospital

5 Neuropathology Department, Sainte Anne Hospital, Paris

6 Centre de Référence National des Cytopénies Autoimmunes de l'Enfant (CEREVANCE), University Hospital of Bordeaux

7 CIC 1401, INSERM CICP, University Hospital of Bordeaux

8 Department of Hematology, APHP - Robert Debré Hospital, Paris, France

9 Department of Pediatric Hematology, University Hospital Timone Enfants, Marseille, France

10 Hôpital des Enfants, University Hospital of Toulouse, Toulouse, France

11 Department of Pediatric Hematology, University Hospital of Poitiers, Poitiers, France

12 Department of Hematology, APHP - Necker-Enfants Malades Hospital

13 Department of Internal Medicine 2, APHP - Pitié-Salpêtrière Hospital, Paris

14 Department of Neurology, APHP - Necker-Enfants Malades Hospital

15 Clinique Neurologique, Pôle des Neurosciences et de l'Appareil Locomoteur, Lille University, France

16 Department of Internal Medicine, University Hospital of Nantes, Nantes, France

17 Department of Internal Medicine, University Hospital Timone Enfants

18 Department of Pediatric Hematology, University Hospital of Bordeaux, Bordeaux, France

*Current address: Department of Pediatric Hematology-Oncology, Sainte-Justine University Hospital, Montreal University, Montréal, Québec, Canada

Word count: Abstract: 250, Text: 2998

Illustration count: Tables: 2, Figures: 4, Supplementary tables: 4, Supplementary figures: 1

Corresponding author:

Thomas Pincez

thomas.pincez@umontreal.ca

Tel: 0015143454788

Fax: 0015143454792 


\section{Abstract}

Purpose Immune thrombocytopenic purpura (ITP) and autoimmune hemolytic anemia (AIHA) are associated in the definition of Evans syndrome (ES). The occurrence of neurological involvement in this population is poorly described and suggests an underlying primary immunodeficiency (PID). We aimed to describe the clinical manifestations, evolution and PID profiles of these patients Methods OBS'CEREVANCE is a French, nationwide prospective cohort that includes children with chronic ITP, AlHA and ES. Patients with a neurological involvement were described. Centralized radiological and pathological reviews and genetic analyses were performed.

Results On October 2016, eight patients (7/181 ES, 1/371 AlHA and 0/615 ITP) were identified, all male, with a median age (range) at cytopenia onset of 11.5 years (1.6-15.8). Neurological symptoms appeared with a median delay of 6 years (2.5-18) after cytopenia and were polymorphic: seizures $(n=4)$, cranial nerve palsy $(n=2)$, Brown-Sequard syndrome $(n=2)$, intracranial pressure $(n=2)$, vertigo $(n=1)$ and/or sensory neuropathy $(n=1)$. Magnetic resonance imaging $(M R I)$ showed inflammatory lesions, confirmed by pathology for five patients with macrophagic or lymphoplasmocytic infiltrates. All patients had other relevant immunopathological manifestations: pulmonary nodules $(n=6)$, lymphoproliferation $(n=4)$, abnormal immunophenotype $(n=8)$ and hypogammaglobulinemia $(n=7)$. Treatment consisted of steroids that improved symptomatology and MRI. Five patients relapsed and three had an asymptomatic radiological progression. A PID was identified in $3 / 8$ patients: 22q11.2 microdeletion $(n=1)$ and CTLA deficiency $(n=2)$.

Conclusion Neurological involvement is a rare and severe late event in the course of childhood ES, which can reveal an underlying PID. Imaging and pathology examination highlight a causative immune dysregulation that may guide targeted therapeutic strategies.

\section{Keywords}

Autoimmune cytopenia, Evans syndrome, primary immunodeficiency, CTLA deficiency, neurological disorder, lymphoproliferation 


\section{Introduction}

Evans syndrome (ES) is defined by the association between Immune thrombocytopenic purpura (ITP) and autoimmune hemolytic anemia (AIHA). These autoimmune cytopenias $(\mathrm{AIC})$ are relatively rare during childhood [1,2]. In France, 10 new cases of ES per year are estimated to be diagnosed in children, 30-50 of AIHA and 500-800 of chronic ITP [3,4]. In an unknown number of cases, AIC can be secondary to an underlying primary immunodeficiency (PID). Classically, the PID that seemed to frequently underlie AIC involved autoimmune lymphoproliferative syndrome, common variable immunodeficiency and Wiskott-Aldrich Syndrome [5-10]. In recent years, alterations of several genes causing PID have been identified in patients with hematological autoimmunity as one of the main manifestations, often preceding other symptoms by years [11-13]. An increasing number of patients with CTLA4/LRBA deficiency, STAT3 gain-of-function mutations or Activated PI3K-delta Syndrome are being described, broadening the spectrum of identified PID $[14,15]$. Consequently, within the childhood AIC population, non-hematological manifestations may be related to a dysimmune process caused by an underlying PID. Their identification is crucial to classifying the disease and for proposing optimal treatment with an adequate follow-up, as well as for improving knowledge about those rare conditions. The characteristics of neurological involvement in these patients are poorly understood. We sought to identify patients with these neurological manifestations among the French cohort of childhood AIC, to describe the clinical radiological and pathological features and their outcomes, and to search for a PID genetic etiology. 


\section{Methods}

\section{Patient selection}

The OBS'CEREVANCE is a nationwide prospective observational cohort (based at the University Hospital of Bordeaux), which includes all consecutive French patients aged less than 18 years presenting with AIHA, chronic ITP or ES since 2004, as described previously $[3,16]$. Written informed consent had been obtained from parents and, when old enough, the patients. The database was declared to the French Commission for Information Technology and Civil Liberties (November 9, 2009, 1396823V0).

\section{Inclusion criteria}

Patients presenting any reported neurological manifestations were first screened through the database in October 2016. Medical records were individually analyzed to confirm or deny their inclusion in the study. Inclusion criteria were any neurological manifestations excluding isolated febrile seizures, symptomatology due to an intracranial hemorrhage or traumatism, and isolated developmental delay.

\section{Data collection}

Clinical and biological data were collected from the original center in charge of the patient. Data collection ceased on April 30, 2017. Autoimmune neutropenia (AIN), the severity and the evolution of AIC used the pre-established definitions $[3,17]$. Lymphocyte phenotype was considered in the absence of concomitant or recent immunosuppressive drugs, and immunoglobulin test before rituximab or 2 years after the last injection. 


\section{Centralized radiological and pathology review}

A centralized review of neurological magnetic resonance imaging (MRI) at the onset and during the follow-up was performed by HDLP (Hospital Trousseau, Paris).

Tissue samples of patients who underwent a cerebral biopsy were collected for centralized pathology review by PV (Hospital Saint-Anne, Paris).

\section{Molecular biology analysis}

A blood sample was collected from the patient. Constitutional DNA was extracted for gene sequencing (FRL, Imagine Institut, Paris). Initially, a candidate gene approach based on the patient phenotype with successive Sanger's method was used. Implementation of panel-based next generation sequencing (NGS) in 2017 allowed simultaneous analysis of 250 PID genes. This home-made panel (designed by $\mathrm{FRL}$ and $\mathrm{BN}$ ) has been made to contain known genes, or ones suspected to be associated with immunopathological manifestations, regardless of the organ involved. Depending on the gene and based on the literature search, the panel encompassed the entire gene sequence, exons or mutational hotspots. NGS DNA gene panel sequencing was performed using Illumina sequencing technology (San Diego, California). A depth of coverage of $>100$ reads was required to determine a variant. A variant was considered to be pathogenic if its pathogenicity had already been described. If pathogenicity had not been described it was assessed through a review of public databases (ClinVar and Human genome variation database) and in silico analysis (PolyPhen6 or the Sorting Intolerant From Tolerant algorithm). Surface staining of the corresponding protein (CTLA4) was used to support NGS findings. Variants not deemed pathogenic were excluded. 


\section{Statistical analysis}

Epidemiological and clinical characteristics of the patients with a neurological involvement were compared to the whole cohort. Categorical data were compared using Fisher's exact test, and continuous data were compared using non-parametric Wilcoxon test. All tests were two-sided with a statistical significance threshold of $p$ $<0.005$; $p$ values between $<0.05$ and $<0.005$ were considered statistically suggestive [18].

\section{Results}

\section{Population}

Among the 1,167 patients (615 ITP, 371 AlHA and $181 \mathrm{ES})$ included in the OBS'CEREVANCE cohort at the time of the selection, eight patients fulfilled the inclusion criteria and all were male. A diagnosis of PID was known in one (incomplete DiGeorge syndrome). They were managed in seven different centers. The median follow-up since AIC onset was 12 years (range 6-26.5).

\section{Autoimmune cytopenia}

Of the eight patients, seven had an ES. Patient 3 had an isolated AIHA (Figure 1). The median age at the first AIC onset was 10.5 years (1.6-15.8, Table 1$)$. The patients with ES demonstrated a median delay between the two with AIC of 1.5 years (0-10.4), and five developed AIN after a median delay of 3.1 years (1-6.9) after first AIC onset. 
All patients received several courses of steroids and all but one intravenous immunoglobulin (IVIG) to manage AIC. Second line immunosuppressive therapies were used in seven children with a median of two (0-5) drugs per patient. The most commonly used was rituximab $(n=7)$. A splenectomy was carried out in two of the patients.

At the last endpoint, all patients were in complete remission of the AlHA and 6/7 in complete remission of the ITP (the last was in partial remission). Nevertheless, only 1/8 had been weaned off of all immunosuppressive medication for more than 12 months.

\section{Epidemiological analysis}

Distribution of cytopenia was different among the eight patients, as compared to the rest of the cohort, with a significantly higher proportion of ES (7/8 vs 174/1159, $p<0.0001)$. The sex ratio of these seven ES patients compared to the 174 others was skewed toward a male predominance (7:0 vs $99: 75, p=0.04)$. No other characteristics were found to be statistically different.

\section{Neurological involvement characteristics}

Polymorphic clinical presentation

The neurological manifestations were observed after AIC onset (median 6 years (2.5-18, Figure 1)). The median age at the appearance of the first symptoms was 17 years (12-26) and three patients developed several (2 to 4) manifestations (Table 2). Within a few days symptoms had developed for each patient. Four patients presented seizures (temporal $(n=2)$, absence $(n=1)$ and/or generalized tonic-clonic episodes $(n=4))$; no one developed status epilepticus. Two patients 
presented with cranial nerve palsy, two had medullary symptomatology with BrownSequard syndrome, two patients had intracranial pressure and one had peripheral vertigo. Patient 8 developed a sensory neuropathy with facial involvement unveiling a stage IVBb EBV-negative Hodgkin lymphoma diagnosis (with bone, hepatosplenic and intracranial involvement). Except for this last case, neurological manifestations were isolated and not coupled to a hematological or immunopathological manifestation.

Initial radiological evaluation: multiple white matter localizations Initial MRI identified unique $(n=2)$ or multiple $(n=6)$ lesions (Figure 2). Six patients had supratentorial lesions involving the white matter. The localization was frontal $(n=3)$, parietal $(n=2)$, temporal $(n=2)$ and/or occipital $(n=1)$. Perilesional edema was present in four cases and was responsible for a median line deviation in two cases. Three patients had subtentorial lesions involving the white matter of the cerebellum and causing an important perilesional edema, amygdala engagement and/or ventricular dilatation. These lesions were associated with supratentorial localization in each case. Two patients had medullar lesions, two had a peripheral lesion and two had a meningeal involvement.

The signal characteristics of all the lesions were similar with T2-hyperintense and T1-iso/hypointense pattern. At least one gadolinium-enhanced lesion was present in seven patients suggesting active injuries. Three patients presented a perivascular topography of the lesions.

Lymphocytic meningitis was concomitant in some patients 
A cerebrospinal fluid (CSF) analysis was conducted for all patients (Table S1). Four had a CSF lymphocytic pleocytosis (median white cells $46 / \mu \mathrm{L}$ (18-102)). One patient had an intrathecal immunoglobulin production. Anti-neuronal antibodies were tested for and returned a negative result for three patients. A lymphocytic phenotype in the CSF was evident for three patients, showing a CD3+ T-cell predominance. The sensory neuropathy of patient 8 was associated with albumin-cytological dissociation in CSF and electromyography parameters showing demyelinating injury. Interictal electroencephalography of patients who presented seizures did not evidence focal abnormalities. No infectious agent was identified in any blood or CSF samples.

\section{Pathology-revealed inflammatory process}

Five patients had a total of four cerebral, three cerebellar and one spinal surgical biopsies (Table S2). A centralized review was performed for the samples of three patients (Figure 3).

All patients presented an inflammatory infiltrate, which had a predominance of macrophages/histiocytes $(n=3)$ or T-lymphocytes/plasmocytes $(n=5)$. In five cases, the infiltrate had a perivascular predominance or a characterized vasculitis and in four cases a granulomatous reaction was observed. A unique macrophage morphology was observed in four samples. No pathogen was found in any sample, nor any indirect sign of infectious process.

\section{Treatment was based on steroids}

Steroid treatment was used as first line therapy for seven patients (Figure 1). Five patients received daily intake (initial dose $1-2 \mathrm{mg} / \mathrm{kg} /$ day then progressive tapering) and three bolus steroids. Four patients received at least one other 
simultaneous therapy associated with steroids: hydroxychloroquine $(n=3)$, methotrexate $(n=2)$, IVIG $(n=2)$, mycophenolate mofetil $(n=2)$.

Steroids allowed an initial clinical and radiological improvement for all cases except patient 1 (who received only bolus steroids) for whom a second line treatment with cyclophosphamide was needed. All patients with seizures required a second line of anti-epileptic treatment to control the recurrence of convulsions.

Patient 8 was treated with IVIG promptly, followed by the chemotherapy for Hodgkin's lymphoma. The neuropathy relapsed 10 months later. New IVIG courses allowed a progressive amelioration.

For three patients, new neurological manifestations appeared during the steroid tapering $(n=1)$ or after the treatment was stopped $(n=2)$. They were sensitive to a new high-dose steroid treatment. Three other patients developed new asymptomatic radiological lesions during the steroid tapering, which were identified on follow-up MRI. Increasing the steroid dose led to these lesions reducing in size.

At the last follow-up (median since the first neurological event: 5 years (310.5)), only two out of five patients could discontinue the daily steroids (at 5 and 30 months of the onset); the remaining three had pursued a continuous treatment for 2 , 5 and 5 years. In two out of five patients, the nonsteroidal immunosuppressive drugs were stopped.

Persistent sequelae during the follow up

At the last endpoint, epilepsy was controlled for four patients (total number of seizures $\leq 5$ per patient) using anti-comitial therapy. 
All five patients who presented non-comitial manifestations displayed clinical sequelae, either minor $(n=2)$, moderate $(n=1)$ or severe $(n=2$, requiring persistent symptomatic treatment).

In all patients, radiological lesions had decreased in size. Nevertheless, at the last radiological assessment, seven patients displayed persistent and stable radiological lesions (median follow-up MRI reviewed: 4 per patient (2-12), Figure S1).

\section{Immunopathological findings}

Non-neurological immunopathological manifestations associated with AIC were present in all patients

All patients developed at least one non-neurological immunopathological manifestation (Figure 4). These manifestations appear a median of 8.5 years $(0-15)$ after AIC onset and before or at the same time as neurological manifestations. The most frequent $(n=6)$ was chronic pulmonary nodules without any proven infection evoking granulomatous-lymphocytic interstitial lung disease (Table S3) [19]. In patient two, pulmonary involvement was a part of a multivisceral granulomatous disease with renal and digestives injuries.

Four patients had non-malignant lymphoproliferation, either superficial $(n=3)$ or profound $(n=3)$. The HL presented by patient 8 had a persistent complete remission at the 30 month follow-up. Four patients presented mucosal or cutaneous injuries, including eczema $(n=3)$ and recurrent diarrhea without an identified etiology evoking immunopathological enteropathy $(n=2)$. Opportunistic or unusual infections were rare. Patient 1 experienced severe chickenpox and patient 5 had streptococcus pneumonia meningitis. 
All patients presented low immunoglobulin levels and/or lymphocyte count

All but one patient presented hypogammaglobulinemia for their age (median IgG: $4.5 \mathrm{~g} / \mathrm{L}(2.7-6))$ associated with $\lg A(n=5)$ and/or $\lg M(n=3)$ deficiency (Table S4). Six received immunoglobulin replacement therapy before the onset of neurological involvement. All patients presented an abnormal lymphocyte phenotype with CD4+ T-cells $(n=5)$, CD8+T-cells $(n=6)$, B-cells $(n=3)$ and/or NK-cells $(n=1)$ deficiency.

\section{Molecular biology}

Genetic analysis was performed on all patients and a PID was identified in three of them (Table 1). Patient one had a DiGeorge syndrome due to a $22 q 11.2$ microdeletion. Two patients presented heterozygous mutations in the CTLA4 gene, located within the exon 2. Both had not been previously described and predicted as pathogenic. Surface staining confirmed the diminution of protein expression. NGS could not have been performed for patient 5 (no follow-up).

\section{Discussion}

Based on this large cohort for AIC appearing in childhood, we demonstrated that neurological manifestations represented a rare occurrence, appearing almost exclusively during the course of ES. The clinical presentation was severe, heterogeneous and caused by a dysimmune process. Despite their initial sensitivity to steroids, all patients presented a chronic evolution and some developed new lesions (symptomatic or not) at the treatment tapering. All of the patients presented miscellaneous immunopathological manifestations and PID was identified in three, including two CTLA4 mutations. 
Literature has rarely reported patients developing neurological manifestations associated with AIC and all but one in adulthood. One case (28 years old) described a lymphoplasmocytic lesion of the encephala before the onset of an ES [20]. Two cases (29 and 53 years) described demyelinating injuries after treatment for ITP (rituximab and splenectomy) $[21,22]$. One patient (44 years) reported with ITP has developed myelitis attributed to a helicobacter infection [23]. Three patients (from a child of unspecified age to 50 years) with ES developed polyradiculoneuropathy (chronic, $n=2$ or acute, $n=1$ ) [24-26]. This scarcity of data is consistent with the low number of patients identified within the OBS'CEREVANCE cohort.

The clinical presentations were acute and polymorphic, related to the lesion topography, which mainly involved the CNS. The MRI morphologies were similar and suggestive of an inflammatory process with an active lesion identified in all but one patient. In this last case (patient 4), the seizure was probably caused by a scar of an unidentified ancient lesion. The dysimmune process was confirmed by the initial work-up and two kinds of immune infiltrates were described by the pathology examination, with either a predominance of lymphoplasmocytic (with T-cells) or macrophagic/histiocytic cells. Interestingly, a very atypical and non-classified macrophage morphology was observed in four of the patients. Granulomas were identified in three patients, which is unusual in AIC [27].

Steroids were the main treatment, used alone or in association, and mostly with a daily intake scheme. The acute and sometimes severe presentation led to injection in the form of a bolus in some patients. This option may represent a good way to be rapidly effective. However, continuous immunosuppression seems necessary in the initial phase (in addition to bolus or alone) because the regrowth of the lesion is seen in some cases as steroid treatment ends or due to tapering. To this 
end, continuous steroids were effective in our cohort but steroid-sparing drugs may represent an alternative treatment. Mycophenolate mofetil (MMF) and sirolimus are effective agents in ES, as a way of limiting steroid utilization [28-31]. Although use of these drugs is still limited in a neurological setting, MMF has been reported to be effective in neuro-sarcoidosis, acute inflammatory polyradiculoneuropathy and multiple sclerosis [32-34]. In one small cohort, sirolimus improved multiple sclerosis lesions [35]. Further data are still required to optimize the management of these drugs. When a specific therapy is available based on the underlying PID, its use may prevent recurrences during steroid tapering and during prolonged treatment courses. The weaning of immunosuppressive drugs can be difficult and a sustained low dose may be required to control the neurological lesions.

Neurological involvement appeared late after the first cytopenia and concerned a particular subgroup, who were different from the "run-of-the-mill" patients with an AIC. This mostly concerned patients with ES, a population with a high probability of underlying PID $[3,36]$. Other immunopathological manifestations were present in all cases but with few infectious manifestations, despite hypogammaglobulinemia and frequent abnormal lymphocyte phenotype. These elements distinguish those patients from early-onset hypogammaglobulinemia, which is usually revealed by infectious manifestations [37].

A PID was identified in three patients. Autoimmunity as a common feature of DiGeorge syndrome and ES has been reported [38-40]. To the best of our knowledge, no dysimmune neurological involvement had been reported. Strikingly, two patients presented a CTLA4 deficiency. Mutations in the CTLA4/LRBA axis were recently described in patients with autoimmune organ injuries, AIC, 
hypogammaglobulinemia and lymphadenopathy/splenomegaly [14,41-44].

Neurological immune infiltration is not uncommon in patients carrying CTLA4 mutations; this concerned 10 of the 133 patients in the largest cohort whereas in two series of patients carrying $L R B A$ mutations, only $1 / 22$ and $3 / 28$ presented such involvement $[14,41,42,44-51]$. The clinical, radiological and pathological features were similar to our cases [41-44]. The identification of these PID provides a unique opportunity for a specific treatment. A substantial clinical amelioration has been reported in patients treated by the Ig-CTLA4 fusion protein abatacept $[14,43,51-53]$. This effect has been specifically described in cerebral lesions [54].

In four cases, no pathological variant was identified. However, their phenotype is highly indicative of an underlying PID. It is plausible that in the near future, the identification of new PIDs or the description and functional analyses of new mutations will allow a better understanding the mechanism of their dysimmunity.

In conclusion, the development of neurological immunopathological manifestations in a patient who presented with an AIC in childhood strongly suggests an underlying PID. Those patients have to be researched from an internist's perspective, concerning other organ immunopathological manifestations and with complete immunologic explorations. The precise pathophysiology of the neurological lesions observed in these patients are not yet fully understood. If the underlying PID can be diverse, our data suggest that a CTLA4 deficiency should be researched, notably because of its great therapeutic impact.

\section{Acknowledgements}


The clinical database OBS'CEREVANCE was funded by the GIS-Institut des Maladies Rares (INSERM), the French Ministry of Health (Rare Disease Plan, PHRC 2005), the Association Bordelaise pour l'Avancement des Sciences Pédiatriques (ABASP) research charity, the Association pour la Recherche et les Maladies Hématologiques de l'Enfant (RMHE) research charity, and the AFSE and O-CYTO patient associations.

\section{Authorship contributions}

TP, BN, JLP, FRL and NA designed the research, analyzed the data and participated in writing the paper. HDLP reviewed the MRI. PV and AG reviewed the pathology samples. HF was the data manager and performed the statistical analyses. FRL performed the biology molecular analyses. BN, JLP, NA, GL, TL, HC, GM, MP, FM, $\mathrm{OH}, \mathrm{AM}, \mathrm{MHu}, \mathrm{HZ}, \mathrm{MHa}, \mathrm{JMD}$ and $\mathrm{YP}$ were in charge of the patients and participated in data and blood sample collection.

All authors critically read the manuscript, approved the final version, and agreed to be accountable for all aspects of the work.

\section{Disclosure of Conflicts of interest}

T.P. has received a funding support from LFB biomedicaments to attend the 2017 European Hematology Association Annual Meeting. The authors declare that they have no other conflict of interest.

\section{References}

1. Terrell DR, Beebe LA, Vesely SK, Neas BR, Segal JB, George JN. The incidence of immune thrombocytopenic purpura in children and adults: A critical review of published reports. Am J Hematol. 2010 Mar;85(3):174-80. 
2. Moulis G, Palmaro A, Montastruc J-L, Godeau B, Lapeyre-Mestre M, Sailler L.

Epidemiology of incident immune thrombocytopenia: a nationwide population-based study in France. Blood. 2014 Nov 20;124(22):3308-15.

3. Aladjidi N, Fernandes H, Leblanc T, Vareliette A, Rieux-Laucat F, Bertrand Y, et al. Evans Syndrome in Children: Long-Term Outcome in a Prospective French National Observational Cohort. Front Pediatr. 2015;3:79.

4. Aladjidi N, Jutand M-A, Beaubois C, Fernandes H, Jeanpetit J, Coureau G, et al. Reliable assessment of the incidence of childhood autoimmune hemolytic anemia. Pediatr Blood Cancer. 2017 Dec;64(12).

5. Seif AE, Manno CS, Sheen C, Grupp SA, Teachey DT. Identifying autoimmune lymphoproliferative syndrome in children with Evans syndrome: a multi-institutional study. Blood. 2010 Mar 18;115(11):2142-5.

6. Zuelzer WW, Mastrangelo R, Stulberg CS, Poulik MD, Page RH, Thompson RI. Autoimmune hemolytic anemia. Natural history and viral-immunologic interactions in childhood. Am J Med. 1970 Jul;49(1):80-93.

7. Savaşan S, Warrier I, Buck S, Kaplan J, Ravindranath Y. Increased lymphocyte Fas expression and high incidence of common variable immunodeficiency disorder in childhood Evans' syndrome. Clin Immunol. 2007 Dec;125(3):224-9.

8. Michel M, Chanet V, Galicier L, Ruivard M, Levy Y, Hermine O, et al. Autoimmune thrombocytopenic purpura and common variable immunodeficiency: analysis of 21 cases and review of the literature. Medicine (Baltimore). 2004 Jul;83(4):254-63.

9. Heeney MM, Zimmerman SA, Ware RE. Childhood autoimmune cytopenia secondary to unsuspected common variable immunodeficiency. J Pediatr. 2003 Nov 1;143(5):662-5.

10. Fischer A, Provot J, Jais J-P, Alcais A, Mahlaoui N. Autoimmune and inflammatory manifestations occur frequently in patients with primary immunodeficiencies. J Allergy Clin Immunol. 2017 Nov 1;140(5):1388-1393.e8.

11. Parvaneh N, Casanova J-L, Notarangelo LD, Conley ME. Primary immunodeficiencies: a rapidly evolving story. J Allergy Clin Immunol. 2013 Feb;131(2):314-23.

12. Seidel MG. Autoimmune and other cytopenias in primary immunodeficiencies: pathomechanisms, novel differential diagnoses, and treatment. Blood. 2014 Oct 9;124(15):2337-44.

13. Bousfiha A, Jeddane L, Picard C, Ailal F, Gaspar HB, Al-Herz W, et al. The 2017 IUIS Phenotypic Classification for Primary Immunodeficiencies. J Clin Immunol. 2018 Jan 1;38(1):129-43.

14. Lo B, Fritz JM, Su HC, Uzel G, Jordan MB, Lenardo MJ. CHAI and LATAIE: new genetic diseases of CTLA-4 checkpoint insufficiency. Blood. 2016 Aug 25;128(8):1037-42. 
15. Elgizouli M, Lowe DM, Speckmann C, Schubert D, Hülsdünker J, Eskandarian Z, et al. Activating PI3K $\delta$ mutations in a cohort of 669 patients with primary immunodeficiency. Clin Exp Immunol. 2016 Feb;183(2):221-9.

16. Aladjidi N, Leverger G, Leblanc T, Picat MQ, Michel G, Bertrand $\mathrm{Y}$, et al. New insights into childhood autoimmune hemolytic anemia: a French national observational study of 265 children. Haematologica. 2011 May 1;96(5):655-63.

17. Buchanan GR, Adix L. Grading of hemorrhage in children with idiopathic thrombocytopenic purpura. J Pediatr. 2002 Nov;141(5):683-8.

18. Benjamin DJ, Berger JO, Johannesson M, Nosek BA, Wagenmakers E-J, Berk R, et al. Redefine statistical significance. Nat Hum Behav. 2018 Jan;2(1):6.

19. Park JH, Levinson Al. Granulomatous-lymphocytic interstitial lung disease (GLILD) in common variable immunodeficiency (CVID). Clin Immunol. 2010 Feb 1;134(2):97-103.

20. Simon OJ, Kuhlmann T, Bittner S, Müller-Tidow C, Weigt J, Wiendl H, et al. Evans syndrome associated with sterile inflammation of the central nervous system: a case report. J Med Case Reports. 2013;7:262.

21. Stübgen J-P. Central nervous system inflammatory demyelination after rituximab therapy for idiopathic thrombocytopenic purpura. J Neurol Sci. 2010 Jan 15;288(12):178-81.

22. Matsui H, Udaka F, Tamura A, Oda M, Kubori T, Nishinaka K, et al. Multiple sclerosis following splenectomy as a treatment for idiopathic thrombocytopenic purpura. Intern Med Tokyo Jpn. 2005 Jul;44(7):747-9.

23. Mizuno H, Sato S, Ohnishi Y, Takahashi T, Nakashima I, Fujihara K, et al. [A case of myelitis with anti-aquaporin 4 antibody concomitant with immune thrombocytopenic purpura]. Rinshō Shinkeigaku Clin Neurol. 2014;54(3):195-9.

24. Guez T, Smadja D, Mas JL, Sicard D. Chronic inflammatory demyelinating polyradiculoneuropathy associated with Evans' syndrome. Eur J Med. 1992 Oct;1(6):374-6.

25. Knecht $H$, Baumberger $M$, Tobòn $A$, Steck $A$. Sustained remission of CIDP associated with Evans syndrome. Neurology. 2004 Aug 24;63(4):730-2.

26. Savaşan S, Warrier I, Ravindranath Y. The spectrum of Evans' syndrome. Arch Dis Child. 1997 Sep 1;77(3):245-8.

27. Sipurzynski J, Fahrner B, Kerbl R, Crazzolara R, Jones N, Ebetsberger G, et al. Management of chronic immune thrombocytopenia in children and adolescents: lessons from an Austrian national cross-sectional study of 81 patients. Semin Hematol. 2016 Apr;53 Suppl 1:S43-47.

28. Miano M, Scalzone M, Perri K, Palmisani E, Caviglia I, Micalizzi C, et al. Mycophenolate mofetil and Sirolimus as second or further line treatment in children with chronic 
refractory Primitive or Secondary Autoimmune Cytopenias: a single centre experience. Br J Haematol. 2015 Oct;171(2):247-53.

29. Bride KL, Vincent T, Smith-Whitley K, Lambert MP, Bleesing JJ, Seif AE, et al. Sirolimus is effective in relapsed/refractory autoimmune cytopenias: results of a prospective multiinstitutional trial. Blood. 2015 Jan 1;blood-2015-07-657981.

30. Miano M, Ramenghi U, Russo G, Rubert L, Barone A, Tucci F, et al. Mycophenolate mofetil for the treatment of children with immune thrombocytopenia and Evans syndrome. A retrospective data review from the Italian association of paediatric haematology/oncology. Br J Haematol. 2016 Nov 1;175(3):490-5.

31. Jasinski S, Weinblatt ME, Glasser CL. Sirolimus as an Effective Agent in the Treatment of Immune Thrombocytopenia (itp) and Evans Syndrome (es): A Single Institution's Experience. J Pediatr Hematol Oncol. 2017 Aug 1;39(6):420-4.

32. Androdias G, Maillet D, Marignier R, Pinède L, Confavreux C, Broussolle $C$, et al. Mycophenolate mofetil may be effective in CNS sarcoidosis but not in sarcoid myopathy. Neurology. 2011 Mar 29;76(13):1168-72.

33. Garssen MPJ, van Koningsveld R, van Doorn PA, Merkies ISJ, Scheltens-de Boer M, van Leusden JA, et al. Treatment of Guillain-Barré syndrome with mycophenolate mofetil: a pilot study. J Neurol Neurosurg Psychiatry. 2007 Sep;78(9):1012-3.

34. Xiao Y, Huang J, Luo H, Wang J. Mycophenolate mofetil for relapsing-remitting multiple sclerosis. Cochrane Database Syst Rev. 2014 Feb 7;(2):CD010242.

35. Bagherpour B, Salehi M, Jafari R, Bagheri A, Kiani-Esfahani A, Edalati M, et al. Promising effect of rapamycin on multiple sclerosis. Mult Scler Relat Disord. 2018 Nov 1;26:40-5.

36. Besnard C, Levy E, Aladjidi N, Stolzenberg M-C, Magerus-Chatinet A, Alibeu O, et al. Pediatric-onset Evans syndrome: Heterogeneous presentation and high frequency of monogenic disorders including LRBA and CTLA4 mutations. Clin Immunol Orlando Fla. 2018 Mar;188:52-7.

37. Brignier AC, Mahlaoui N, Reimann C, Picard C, Kracker S, de Vergnes N, et al. Earlyonset hypogammaglobulinemia: A survey of 44 patients. J Allergy Clin Immunol. 2015 Oct;136(4):1097-1099.e2.

38. Tison BE, Nicholas SK, Abramson SL, Hanson IC, Paul ME, Seeborg FO, et al. Autoimmunity in a cohort of 130 pediatric patients with partial DiGeorge syndrome. J Allergy Clin Immunol. 2011 Nov 1;128(5):1115-1117.e3.

39. Colarusso G, Gambineri E, Lapi E, Casini T, Tucci F, Lippi F, et al. Evans syndrome and antibody deficiency: an atypical presentation of chromosome 22q11.2 deletion syndrome. Pediatr Rep [Internet]. 2010 Sep 6 [cited 2017 Mar 18];2(2). Available from: http://www.ncbi.nlm.nih.gov/pmc/articles/PMC3094001/ 
40. Kratz CP, Niehues T, Lyding S, Heusch A, Janssen G, Göbel U. Evans syndrome in a patient with chromosome 22q11.2 deletion syndrome: a case report. Pediatr Hematol Oncol. 2003 Mar;20(2):167-72.

41. Kuehn HS, Ouyang W, Lo B, Deenick EK, Niemela JE, Avery DT, et al. Immune dysregulation in human subjects with heterozygous germline mutations in CTLA4. Science. 2014 Sep 26;345(6204):1623-7.

42. Schubert D, Bode C, Kenefeck R, Hou TZ, Wing JB, Kennedy A, et al. Autosomal dominant immune dysregulation syndrome in humans with CTLA4 mutations. Nat Med. 2014 Dec;20(12):1410-6.

43. Lo B, Zhang K, Lu W, Zheng L, Zhang Q, Kanellopoulou C, et al. Patients with LRBA deficiency show CTLA4 loss and immune dysregulation responsive to abatacept therapy. Science. 2015 Jul 24;349(6246):436-40.

44. Lopez-Herrera G, Tampella G, Pan-Hammarström Q, Herholz P, Trujillo-Vargas CM, Phadwal K, et al. Deleterious Mutations in LRBA Are Associated with a Syndrome of Immune Deficiency and Autoimmunity. Am J Hum Genet. 2012 Jun 8;90(6):986-1001.

45. Alangari A, Alsultan A, Adly N, Massaad MJ, Kiani IS, Aljebreen A, et al. LPS-responsive beige-like anchor (LRBA) gene mutation in a family with inflammatory bowel disease and combined immunodeficiency. J Allergy Clin Immunol. 2012 Aug;130(2):481-488.e2.

46. Burns SO, Zenner HL, Plagnol V, Curtis J, Mok K, Eisenhut M, et al. LRBA gene deletion in a patient presenting with autoimmunity without hypogammaglobulinemia. J Allergy Clin Immunol. 2012 Dec;130(6):1428-32.

47. Seidel MG, Hirschmugl T, Gamez-Diaz L, Schwinger W, Serwas N, Deutschmann A, et al. Long-term remission after allogeneic hematopoietic stem cell transplantation in LPSresponsive beige-like anchor (LRBA) deficiency. J Allergy Clin Immunol. 2015 May;135(5):1384-1390.e1-8.

48. Charbonnier L-M, Janssen E, Chou J, Ohsumi TK, Keles S, Hsu JT, et al. Regulatory T-cell deficiency and immune dysregulation, polyendocrinopathy, enteropathy, X-linked-like disorder caused by loss-of-function mutations in LRBA. J Allergy Clin Immunol. 2015 Jan;135(1):217-27.

49. Hayakawa S, Okada S, Tsumura M, Sakata S, Ueno Y, Imai K, et al. A Patient with CTLA-4 Haploinsufficiency Presenting Gastric Cancer. J Clin Immunol. 2016 Jan;36(1):28-32.

50. Gámez-Díaz L, August D, Stepensky P, Revel-Vilk S, Seidel MG, Noriko M, et al. The extended phenotype of LPS-responsive beige-like anchor protein (LRBA) deficiency. J Allergy Clin Immunol. 2016 Jan 1;137(1):223-30.

51. Schwab C, Gabrysch A, Olbrich P, Patiño V, Warnatz K, Wolff D, et al. Phenotype, penetrance, and treatment of 133 CTLA-4-insufficient individuals. J Allergy Clin Immunol. 2018 May 4; 
52. Notarangelo LD, Fleisher TA. Targeted strategies directed at the molecular defect: Toward precision medicine for select primary immunodeficiency disorders. J Allergy Clin Immunol. 2017 Mar;139(3):715-23.

53. Lee $\mathrm{S}$, Moon JS, Lee C-R, Kim H-E, Baek S-M, Hwang S, et al. Abatacept alleviates severe autoimmune symptoms in a patient carrying a de novo variant in CTLA-4. J Allergy Clin Immunol. 2016 Jan;137(1):327-30.

54. van Leeuwen EM, Cuadrado E, Gerrits AM, Witteveen E, de Bree GJ. Treatment of Intracerebral Lesions with Abatacept in a CTLA4-Haploinsufficient Patient. J Clin Immunol. 2018 May 23;

\section{Tables}

\begin{tabular}{|c|c|c|c|c|c|c|c|c|c|c|c|c|c|c|}
\hline \multirow[b]{2}{*}{ Patient } & \multirow[b]{2}{*}{$\begin{array}{l}\text { Cytopenia } \\
\text { sequence }\end{array}$} & \multicolumn{3}{|c|}{ Age at diagnosis (years) } & \multirow[b]{2}{*}{ DAT } & \multicolumn{2}{|c|}{$\begin{array}{l}\text { Severity at } \\
\text { diagnosis }\end{array}$} & \multicolumn{4}{|c|}{ Treatments } & \multicolumn{2}{|c|}{ Evolution } & \multirow[b]{2}{*}{ Genetic alteration } \\
\hline & & First AIC & $\begin{array}{l}\text { Second } \\
\text { AIC }\end{array}$ & AIN & & AlHA & ITP & CS & IV Ig & IS (nb) & SPX & AlHA & ITP & \\
\hline 1 & $\begin{array}{c}\text { Simultaneous } \\
\text { ES }\end{array}$ & \multicolumn{2}{|c|}{15.8} & 18.5 & $\lg G$ & 1 & 0 & Yes & Yes & 2 & No & $\mathrm{CR}$ & PR & 22q11.2 microdeletion * \\
\hline 2 & $\begin{array}{c}\text { Simultaneous } \\
\text { ES }\end{array}$ & \multicolumn{2}{|c|}{11.1} & 14.2 & $\lg G$ & $\mathrm{~N} / \mathrm{A}$ & $\mathrm{N} / \mathrm{A}$ & Yes & No & 0 & No & $\mathrm{CR}$ & $\mathrm{CR}$ & $\begin{array}{c}\text { Heterozygous CTLA4 mutation } \\
\text { c.316A>C; p.T106P }\end{array}$ \\
\hline 3 & AlHA & 15.6 & $\mathrm{~N} / \mathrm{A}$ & N/A & $\begin{array}{l}\lg G \\
+\mathrm{C} 3\end{array}$ & 2 & $\mathrm{~N} / \mathrm{A}$ & Yes & Yes & 1 & No & $\mathrm{CR}$ & $\mathrm{N} / \mathrm{A}$ & $\begin{array}{c}\text { Heterozygous CTLA4 mutation } \\
\text { c.403dupA; p.Y135fsX }\end{array}$ \\
\hline 4 & ITP then AIHA & 1.6 & 12 & $\mathrm{~N} / \mathrm{A}$ & $\lg G$ & 1 & 2 & Yes & Yes & 5 & No & $\mathrm{CR}$ & $\mathrm{CR}$ & $\begin{array}{c}\text { No pathogenic mutation identified in } \\
\text { the panel of } 250 \text { genes }\end{array}$ \\
\hline 5 & ITP then AIHA & 10 & 15.7 & 15.5 & $\begin{array}{l}\text { IgG } \\
+\mathrm{C} 3\end{array}$ & 2 & 2 & Yes & Yes & 2 & Yes & $\mathrm{CR}$ & $\mathrm{CR}$ & $\begin{array}{c}\text { No pathogenic mutation in RAG1 } \\
\text { and RAG2 }\end{array}$ \\
\hline 6 & ITP then AIHA & 3.5 & 12.4 & $\mathrm{~N} / \mathrm{A}$ & $\lg G$ & $\mathrm{~N} / \mathrm{A}$ & $\mathrm{N} / \mathrm{A}$ & Yes & Yes & 2 & No & CCR & CCR & $\begin{array}{c}\text { No pathogenic mutation identified in } \\
\text { the panel of } 250 \text { genes }\end{array}$ \\
\hline 7 & AlHA then ITP & 7.6 & 9.8 & 14.5 & $\begin{array}{l}\lg G \\
+\mathrm{C} 3\end{array}$ & 2 & 2 & Yes & Yes & 4 & No & $\mathrm{CR}$ & PR & $\begin{array}{c}\text { No pathogenic mutation identified in } \\
\text { the panel of } 250 \text { genes }\end{array}$ \\
\hline 8 & ITP then AIHA & 13 & 14 & 14 & $\lg G$ & 1 & 3 & Yes & Yes & 3 & Yes & $\mathrm{CR}$ & CR & $\begin{array}{c}\text { No pathogenic mutation identified in } \\
\text { the panel of } 250 \text { genes }\end{array}$ \\
\hline
\end{tabular}

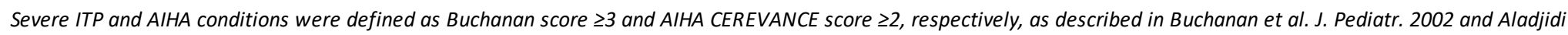
et al. Front. Pediatr. 2015, respectively.

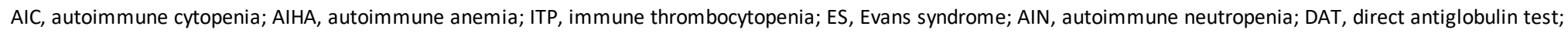

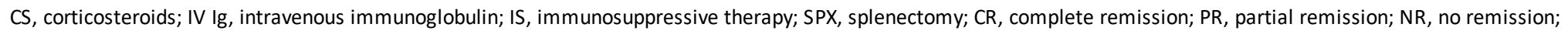
$\mathrm{CCR}$, continuous complete remission; N/A, not applicable; nb, number.

Table 1 Description of AIC and genetic analyses 
Lesion of the whole spinal cord with T3-T5 gado+ lesion associated to $\mathrm{T} 4$ spondylitis. Five supratentorial micronodular lesions (gado+)
Transient amelioration after ST (bolus) and IVIG. Improvement after 6 cyclophosphamide cycles. Persistence of incomplete spastic paraplegia with chronic urinary retention. Treatment by baclofen, dantrolene and surgery.
1) Posterior fossa nodular lesions (gado+). 2) Multiple supra- and subtentorial lesions. 3 ) Right cerebellum lesion with meningeal involvment (gado+)
Three manifestations treated succesfully by ST (daily). No more recurrence under lacosamide, levetiracetam, prednisone and methotrexate.
1) Bilateral temporal lesions (gado+) 2) Left parietal lesion (gado+
Two manifestations succesfully treated by ST (daily). No more recurrence under lacosamide, levetiracetam, prednisone, hydroxychloroquine.
1) Temporal and generalized

3 tonic-clonic seizure 2) Generalized tonic-clonic seizures Temporal and generalized tonic-clonic seizures
Bilateral temporal lesions (gado-)
ST (daily) for 5 months, switch from cyclosporine to mycophenolate mofetil, stable lesion. Three seizure recurrences under levetiracetam.

1) Anosmia, right oculomotor nerve palsy. 2) Intracranial hypertension.

3) Rotatory vertigo. 4) Intracranial hypertension

Left VI and VII cranial nerve palsy associated with intracranial hypertension
1) Right infiltrative frontoethmoidal lesion (gado+) with pachymeningitis. 2) Left cerebellar lesion (gado+). 3) Left auditory canal lesion (gado+). 4) Right cerebellar lesion (gado+)

Posterior fossa tissue lesion (gado+). Right periventricular lesion (gado-)
Four episodes treated successfully with ST (daily) \pm methotrexate \pm hydroxychloroquine. Persistence of nystagmus. Loss to follow-up.

Clinical improvement after ST (bolus + daily). Persisting sequels of facial palsy. Eight new asymptomatic supratentorial lesions (gado \pm ) appeared during follow-up; regression under ST dose increase (daily).

Left cervical spinal cord lesion ( $\mathrm{C} 5$ to $\mathrm{T} 2$ ) swelling (heterogeneous gado+). Whole spinal cord
Clinical amelioration under ST (bolus). Persistence of sequelae (dysesthesia, partial motor deficit, dysuria) requiring therapy with duloxetine, clonazepam, pregabaline, and tramadol.
7 Incomplete left Brown-Séquard + homolateral Horner's syndrome
Bilateral gadolinium-enhancement of intracranial portion of cranial nerves $\mathrm{V}$. Vertebral lesions related to $\mathrm{HL}$
Delayed amelioration following IV IG and chemotherapy

Relapse, progressive amelioration with IV Ig. Persistent

sensory disorders of all four limbs, occasional treatment with clonazepam. ataxia)

Sensory ganglionopathy (Cranial nerves III, IV, V and VI palsy with troublesproblems and proprioceptive

Gado+, gadolinium enhancement; Gado-, no gadolinium enhancement; Gado \pm , gadolinium enhancement of some of the lesions; CSF, cerebrospinal fluid; N/A, not applicable.

\section{Table 2 Neurological involvement and evolution}




\section{Figures}
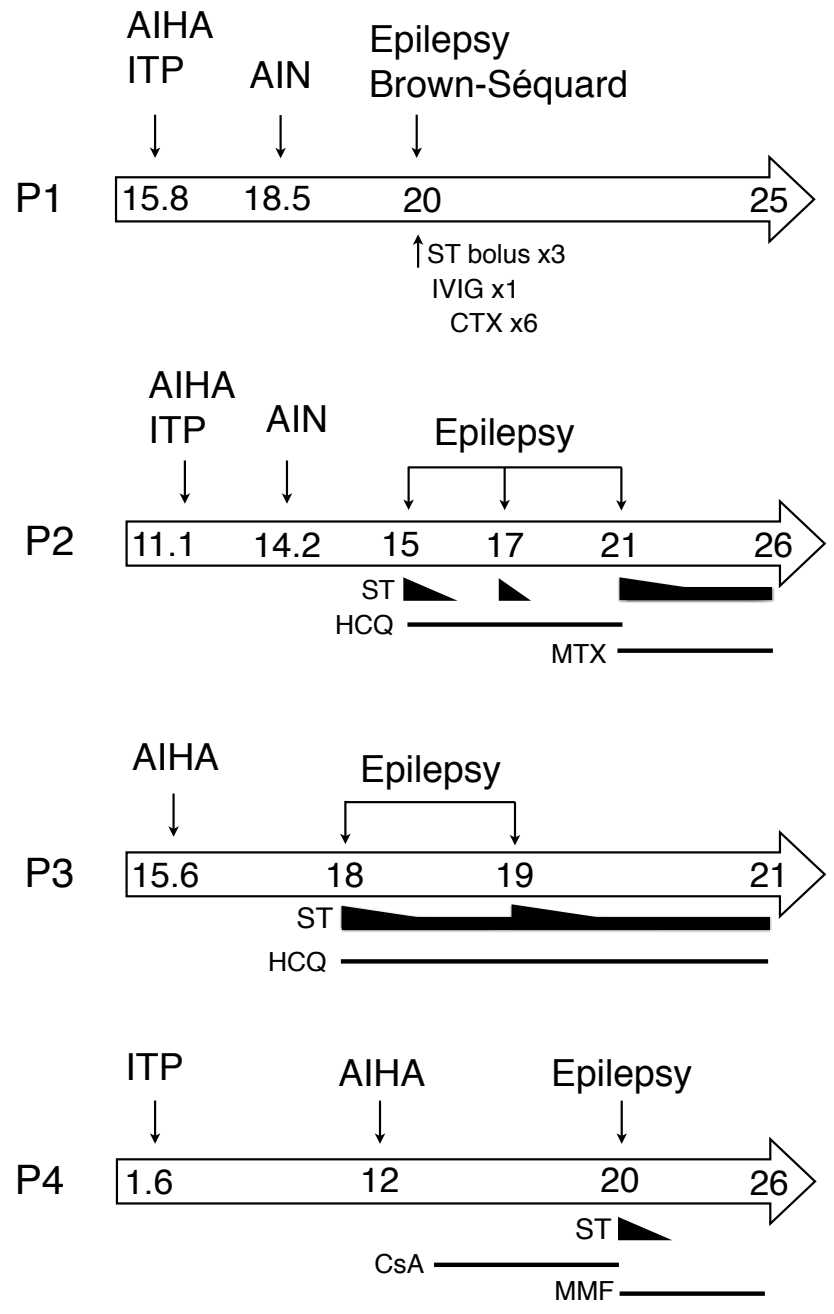
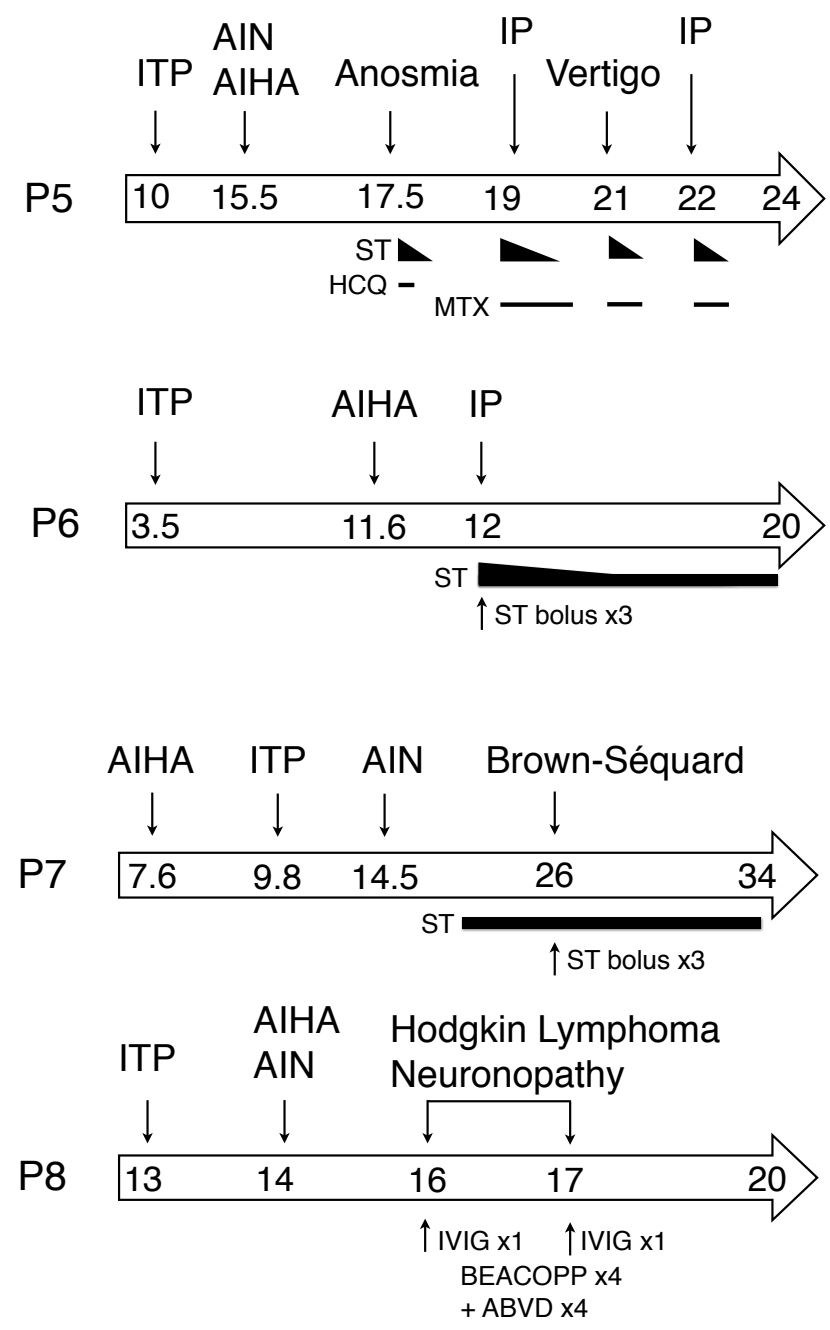

Figure 1 Clinical courses of the patients

Individual representation of the manifestations' clinical sequence. Age at the onset (years) is specified for each manifestation. Time scale is not representative. Each treatment used for the neurological involvement is represented below. ITP: immune thrombocytopenic purpura. ST: steroids therapy. IVIG: intravenous immunoglobulins. CTX: cyclophosphamide. HCQ: hydroxychloroquine. IP: Intracranial pressure. MTX: methotrexate. CsA: cyclosporine. MMF: mycophenolate mofetil. BEACOPP: Bleomycin, Etoposide, Doxorubicin, Cyclophosphamide, Vincrsitine, Procarbazine, Prednisone (1.33mg/kg/day for 14 days). ABVD:

Doxorubicin, Bleomycin, Vinblastine, Dacarbazine. 

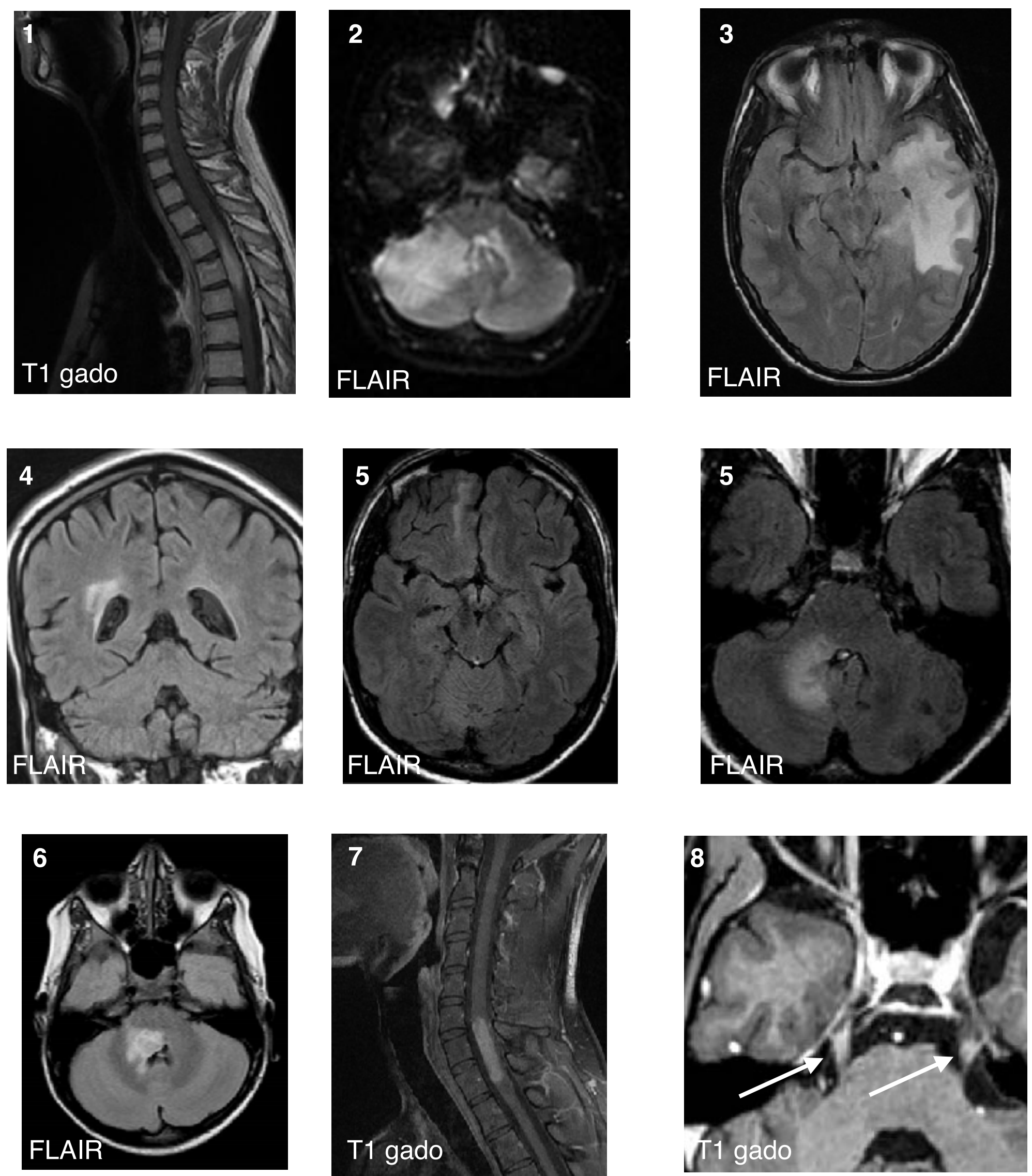
Figure 2 Representative neurological MRI of patients

Individual MRI at the manifestation onset (two distinct manifestations for patient 5).

Each patient's ID is the upper number and the MRI sequence is the lower statement (T1 gado: T1-weighted sequence post gadolinium injection, FLAIR: T2-weighted sequence fluid-attenuated inversion recovery). For patient 8 , the arrows show gadolinium-enhancement of both intracranial portions of cranial nerve $\mathrm{V}$.

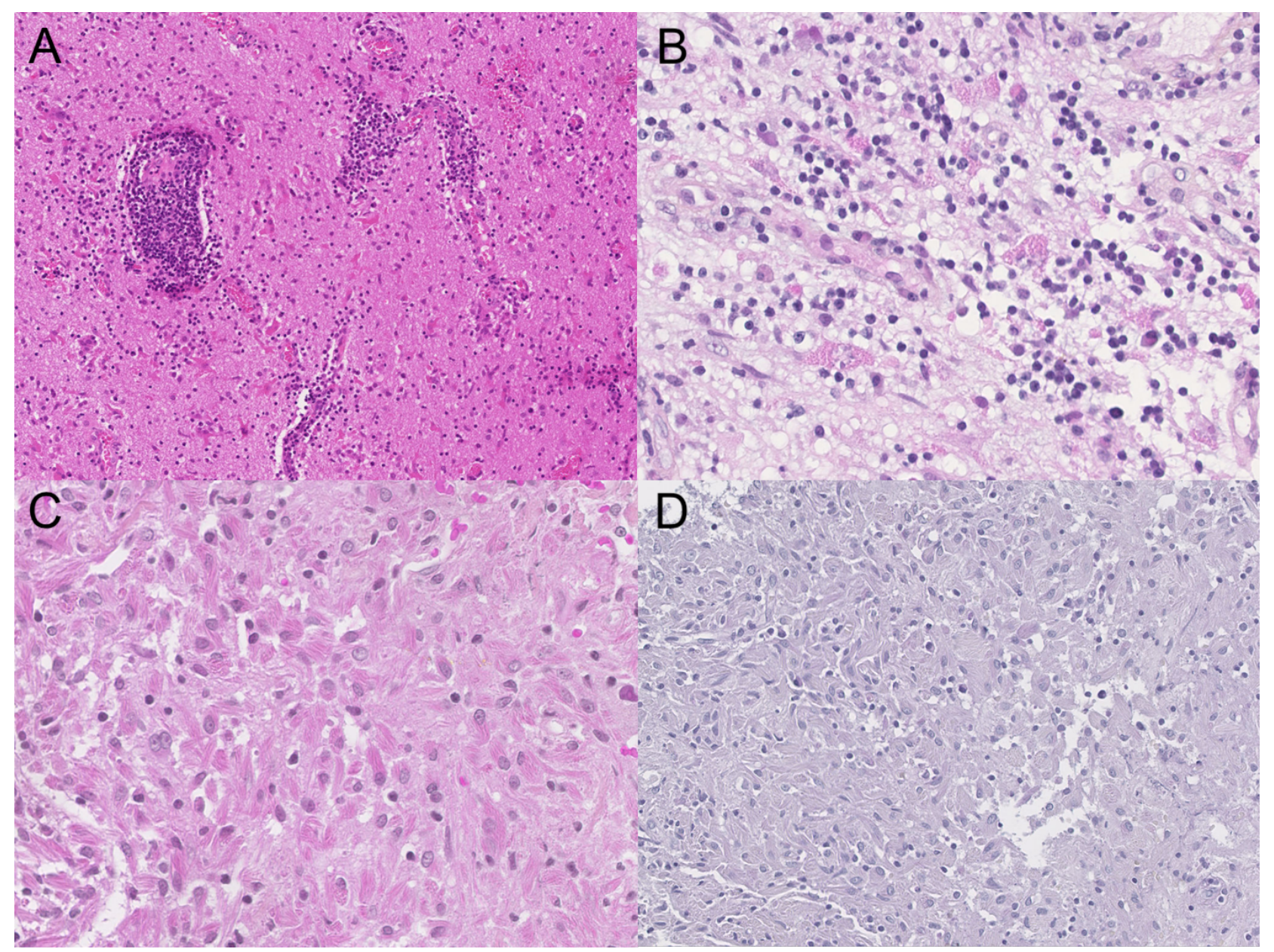

Figure 3 Representative histological samples

A) The three patients reviewed presented pleomorphic pseudo-tumoral masses, which were mono-lymphocytic and plasmocytic, with vasculitis and without necrosis (Patient 5, x100). B) The inflammatory reaction contained numerous and dispersed microgranular macrophages in poorly defined clusters (Patient 2, x300). C) Some macrophages presented a striated aspect (Patient 6, x300). D) Periodic Acid-Schiff reaction was negative on these macrophages (Patient $6, x 200$ ). 


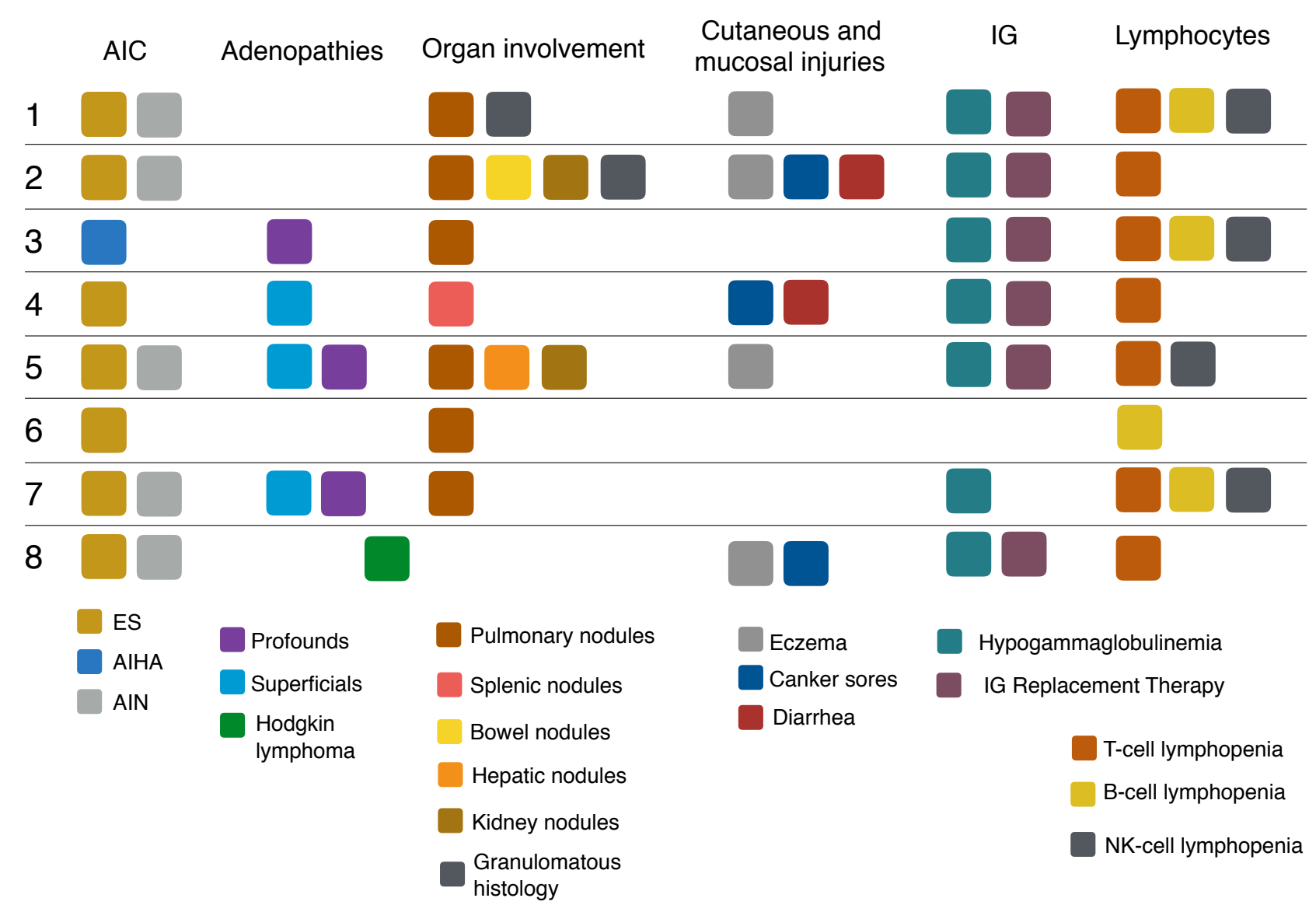

Figure 4 Non-neurological characteristics of the patients

Individual summaries of the autoimmune cytopenia, non-neurological manifestations and immunological features of the patients. The complete descriptions are available in Table 1 (description of AIC and genetic analyses), Table S3 (non-neurological organ involvement) and Table S4 (immunobiology).

AIC: autoimmune cytopenia. ES: Evans syndrome. AIHA: autoimmune hemolytic anemia. AIN: autoimmune neutropenia. IG: immunoglobulins. 
Supplementary Material

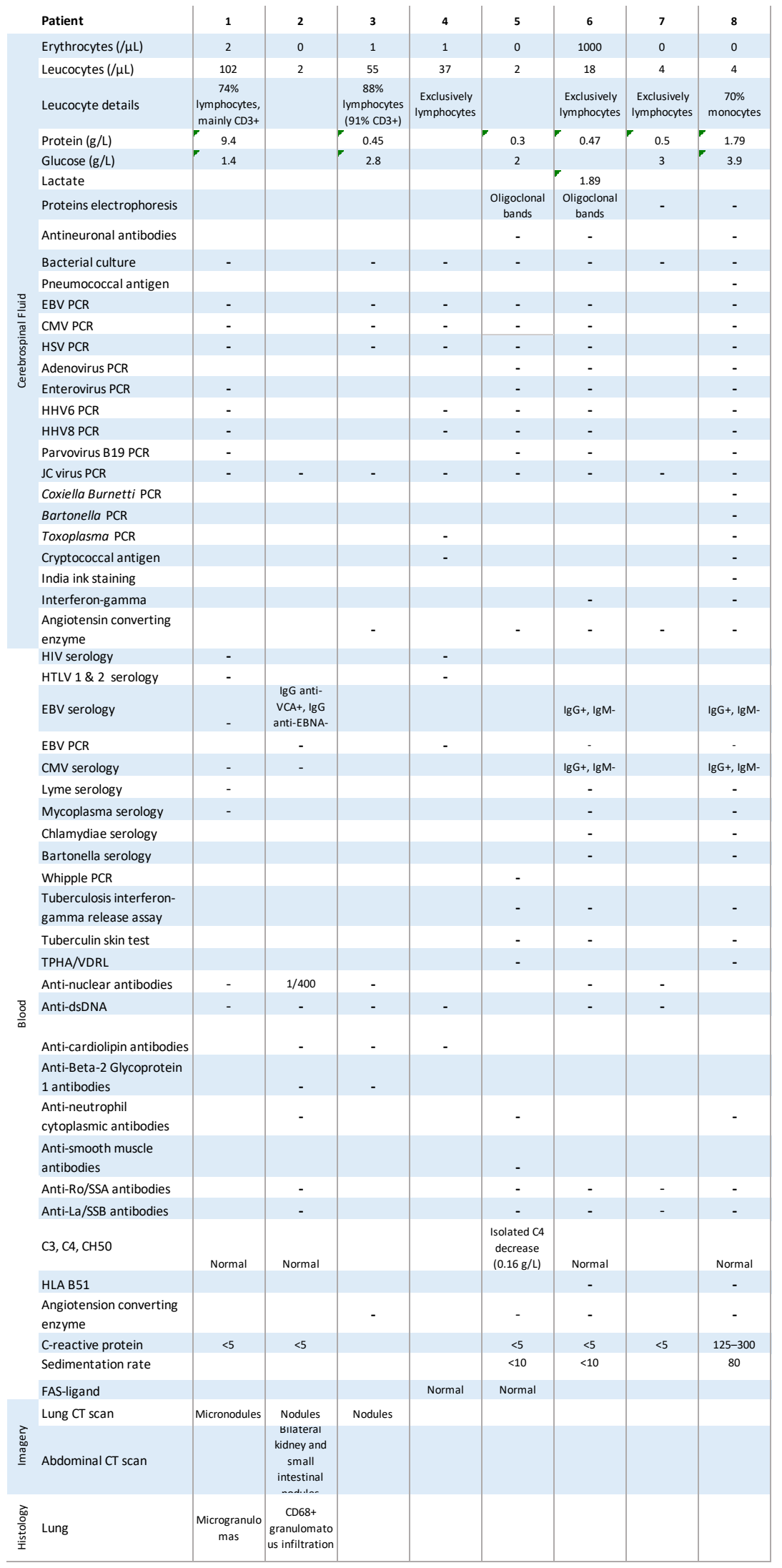

Table S1 Complementary exams at neurological involvement 
Patient Pathology

1 Spine biopsy: perivascular lymphoplasmocytic infiltrate, CD20-CD3+. Cerebrum biopsy: Iymphoplasmocytic infiltrate, mainly perivascular, CD20-CD3+

2 (1) Cerebellum biopsy: granulomatous lymphoplasmocytic infiltrate. (2)* Cerebellum biopsy: plasma cell-rich granuloma with unusual CD68+ macrophage reaction

(1) Cerebrum biopsy: perivascular lymphoplasmocytic granulomatous process. (3)

3 Perivascular lymphoplasmocytic infiltrate compatible with vasculitis. Numerous $\mathrm{C68+}$ CD1A-macrophages with unusal aspects

4

No biopsy performed

(1) Cerebrum biopsy: polymorphic infiltrate with a predominance of CD68+CD1ahistiocytes. Numerous CD3+lymphocytes and CD138+CD79a+CD20-plasmocytes.

$5 \quad(2) *$ Cerebellum biopsy: perivascular CD3+ lymphocytic infiltrate (few CD138+ CD20plasmocytes and small CD20+CD79+B lymphocytes) with granulomatous reaction.

CD68+ microglial activation

Brainstem biopsy*: Perivascular monolymphocytic CD68+CD3+infiltrate with CD168+ plasmocytes.

No biopsy performed

8

No biopsy performed

* Samples centrally reviewed

\section{Table S2 Pathology findings}


Patient Personal and familial history

22q11.2 microdeletion with IVC,

1

testicular ectopia, psychomotor retardation and bilateral camptodactyly
Adenopathies and organomegalies

$\begin{array}{ccc}\text { Organ injuries } & \begin{array}{c}\text { Cutaneous and mucosal } \\ \text { involvement }\end{array} & \begin{array}{c}\text { Severe or unusual } \\ \text { infection }\end{array} \\ \text { Pulmonary nodules }(\mathrm{H}: \text { microgranulomas) }(20 & \text { Eczema }(19 \mathrm{y}) & \begin{array}{c}\text { Severe chickenpox (18 } \\ \text { y) }\end{array}\end{array}$

2

\begin{abstract}
None
\end{abstract}

(n)

\section{Mother: Gougerot-Sjögren syndrome}

Supra and infra diaphragmatic adenopathies $(18 y)$. Splenic nodules $(18 y)$

4 Mother: Systemic lupus erythematous Fluctuating superficial
adenopathies $(20 \mathrm{y})$
Pulmonary nodules (no histology, normal BAL)

(18 y)

\section{Multivisceral granulomatous disease}

(pulmonary, intestinal and renal nodules) (pulmonary $\mathrm{H}$ : granulomatous macrophage inflitration) (15 y). Noninfectious unilateral uveitis, corticosensitive $(20 \mathrm{y})$. Major asthenia
Fluctuating diarrhea, no etiology found (16y). Eczema (17y)
Axillar, mediastinal, pulmonary Pulmonary nodules. Normal BAL. Chisholm and abdominal adenopathies. grade III LSG. $(15 y)$ Femoral asymptomatic ( $H$ : nonspecific follicular bone lesions, evoking former bone infarct (17 hyperplasia) (15 y)
$5 \quad$ None

None

$$
\text { y) }
$$
6
None
Pulmonary bilateral micronodules. Non-
contributive BAL (11 y)

$\begin{array}{ccc}\text { None } & \begin{array}{c}\text { Superficial adenopathies. } \\ \text { Lateroaortic adenopathy ( } \mathrm{H}: \\ \text { nonspecific adenopathy). }(26 \mathrm{y}) \\ \text { Splenomegaly }(8 \mathrm{y})\end{array} & \begin{array}{c}\text { Pulmonary nodules. BAL: hypercellularity } \\ \left(850000 / \mathrm{mm}^{3}\right), 27 \% \text { lymphocytes. Chisholm } \\ \text { grade IV LSG }(26 y)\end{array} \\ 8 & \text { None } & \text { Kodgkin lymphoma EBV- stage IV Bb (bones, liver, splenic and intracranial } \\ \text { involvement) }\end{array}$
Diarrhea episodes, no etiology
found $(22 y)$. Recurrent urticaria
$(24 y)$
Post-splenectomy pneumococcus bacteremia (and probably meningitis) with no prophylaxis (19

Age at diagnosis of manifestation is shown in parentheses.

IVC:, intraventricular communication,; H:, histology,; BAL:, bronchoalveolar lavage,; LSG:, labial salivary gland.

Table S3 Non-neurological organ involvement 


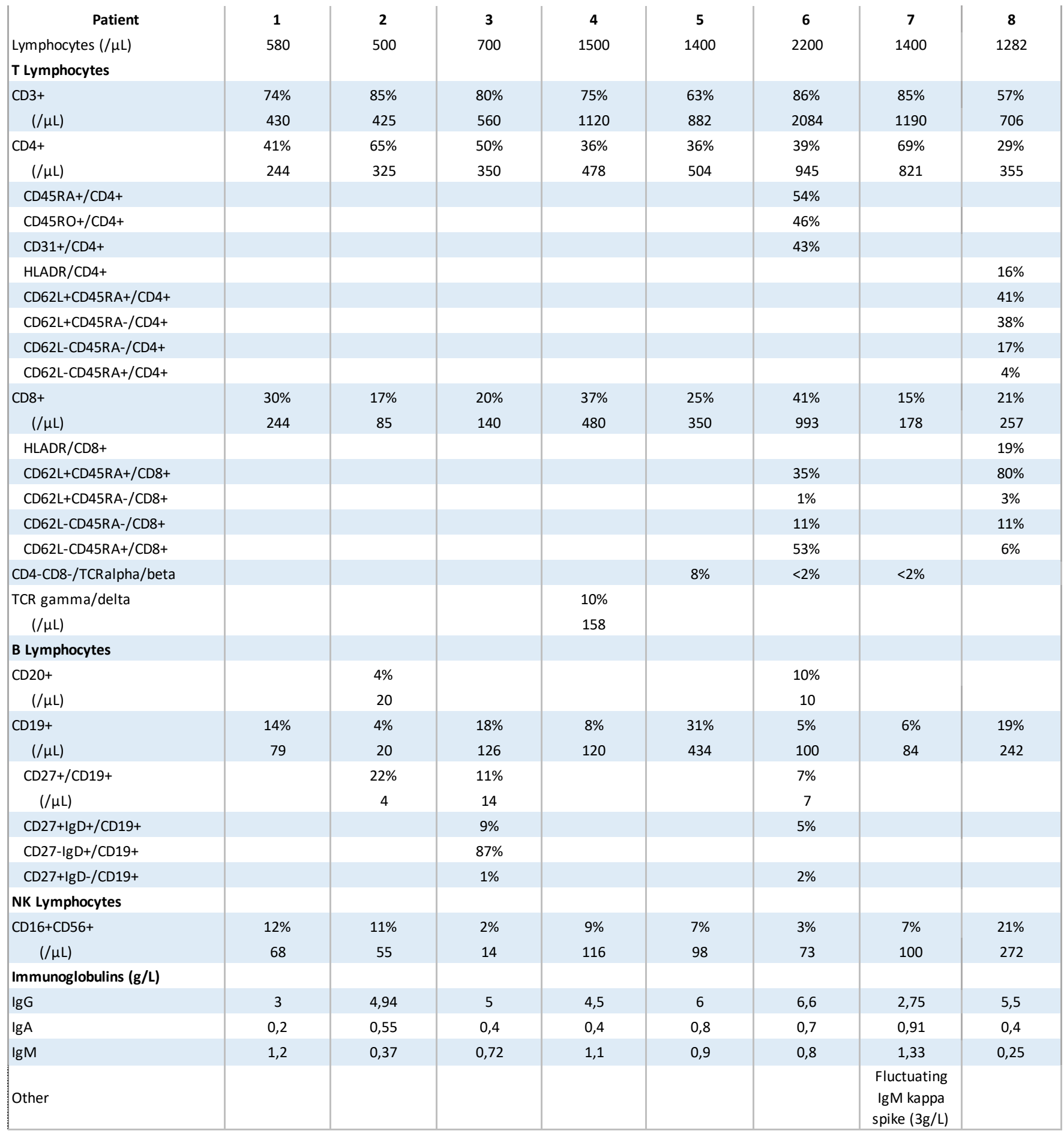

Table S4 Immunobiology 


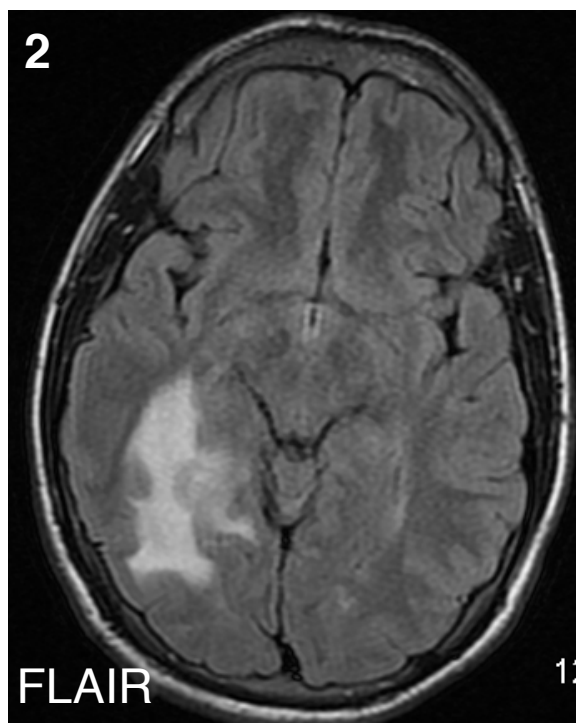

1.5 years

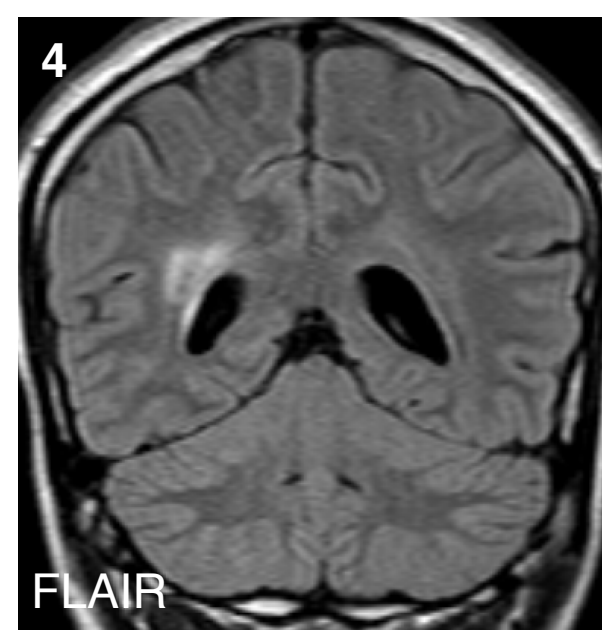

5 years

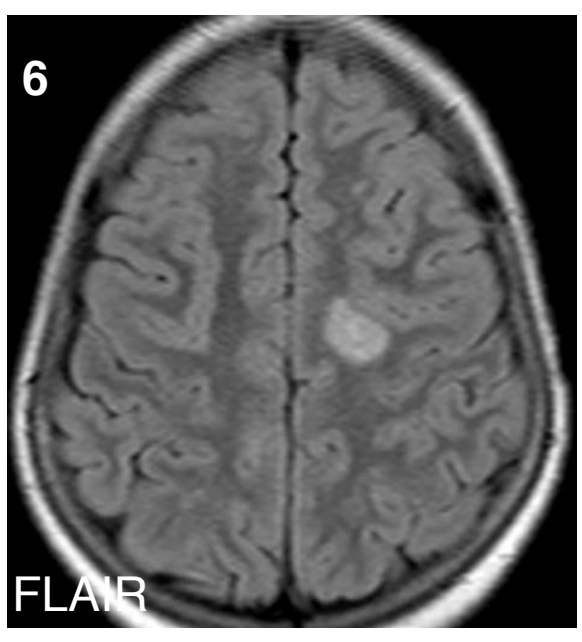

5 years

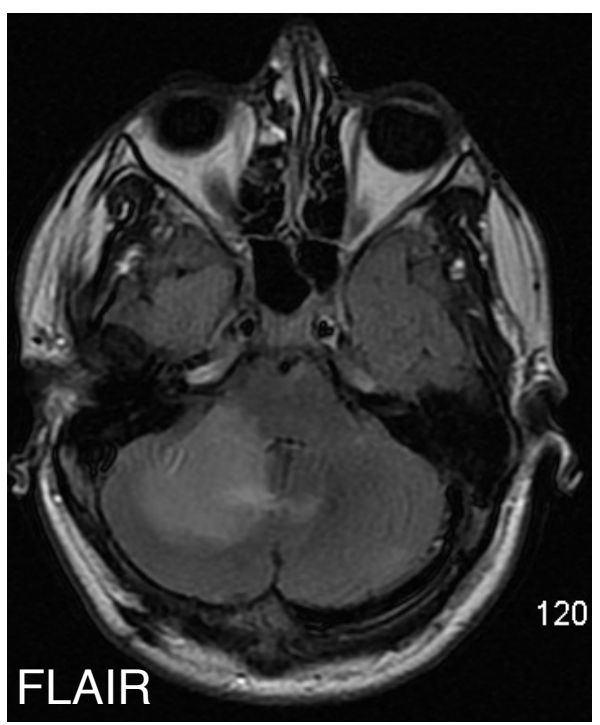

5.5 years

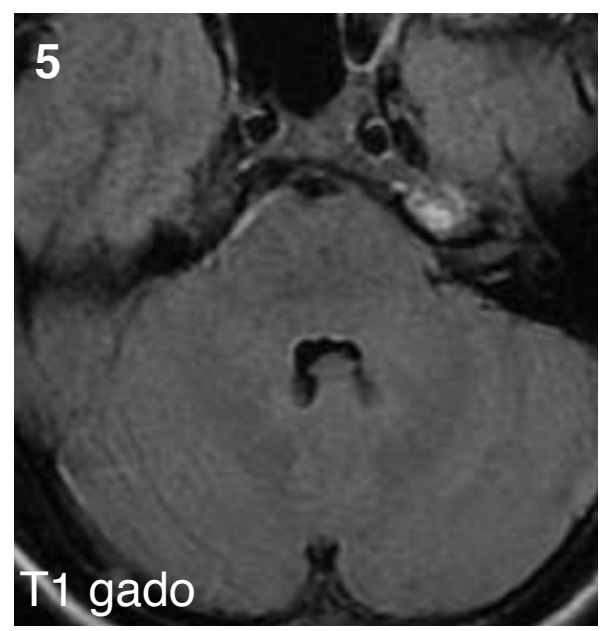

4 years

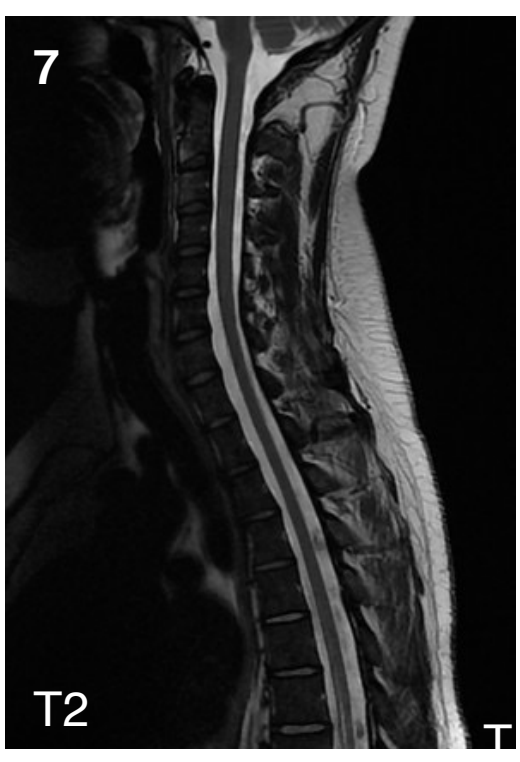

5 years

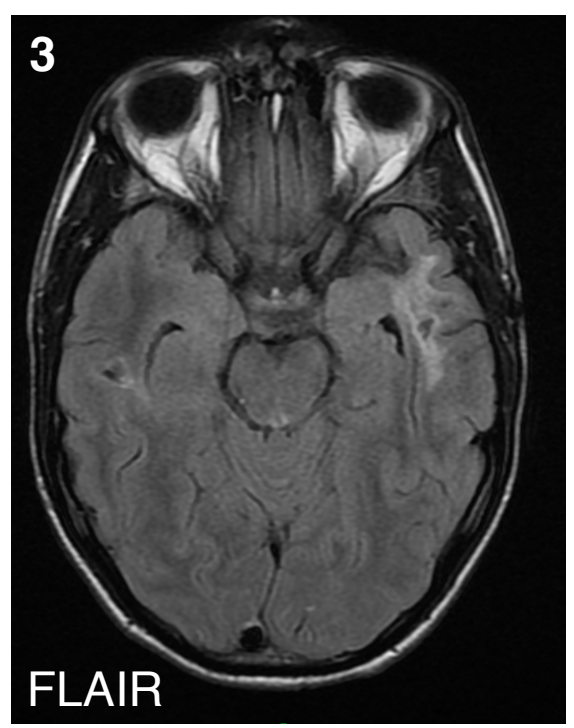

18 months

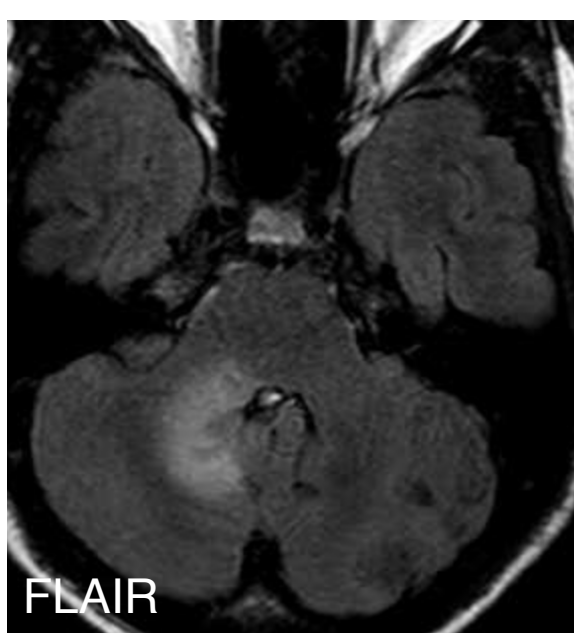

5 years

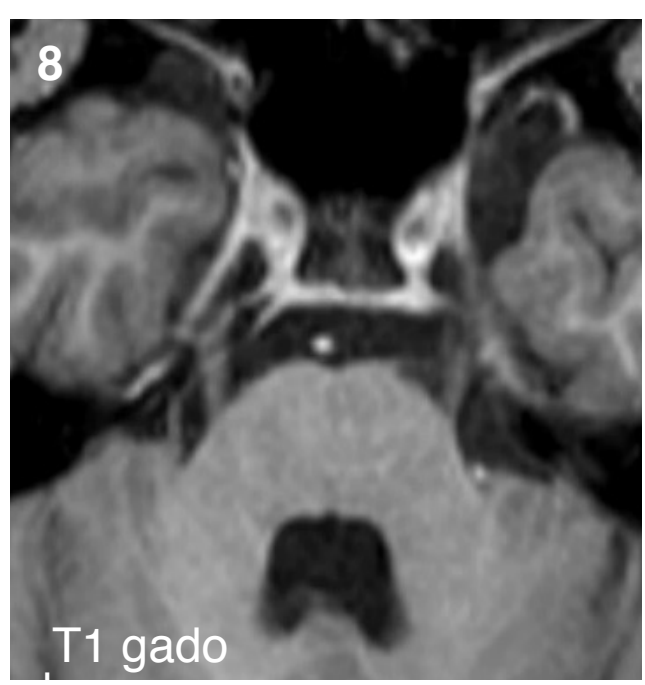

1 year 
Figure S1 Radiological evolution of the lesions

Each patient's ID is the upper number and the MRI sequence is the lower statement (T1 gado: T1-weighted sequence post gadolinium injection, FLAIR: T2-weighted sequence fluid-attenuated inversion recovery). The delay after manifestation's onset is under each figure. 